\title{
PSEUDOMONAS AERUGINOSA INFECTION IN CYSTIC FIBROSIS PATIENTS
}

\author{
AHMED SAKS ${ }^{1}$, DOOLEY JSG ${ }^{2}$, DEB SR $^{3}$, TALUKDER DC $^{4}$, HOSSAIN SS $^{5}$, ANWAR ASMT ${ }^{6}$
}

\begin{abstract}
:
Cystic Fibrosis is an autosomal recessive genetic disease where the lung is heavily colonized by biofilm forming Pseudomonas aeruginosabacteria. Biofilm due to its thick wall and presence of extracellular polymeric substances confers bacteria with a much higher resistance against antimicrobial compounds and environmental stress. Research has revealed the presence of extracellular DNA (eDNA) in significant amounts in the biofilm walls of such bacteria. Although the exact role of eDNA has not been elucidated but research prompts that eDNA to have significant role in stabilizing the biofilm complex structure as well as providing the bacteria with resistance against antimicrobial and antibiotic compounds. The presence of eDNA prompted research to use DNase as a biofilm destabilizing agent. Under experimental conditions, DNase has shown to dissolve early forming biofilm walls especially when used in combination with antibiotics therefore suggesting the use of DNase as an effective treatment strategy in CF patients. But ambiguity arises when some recent studies showed that $\mathrm{P}$. aeruginosa can opportunistically use DNase for its survival advantage by using the enzyme to access phosphate, carbon and nitrogen constituentsof the DNA in nutrient limited conditions; and also by using the DNase to degrade the DNA component of neutrophil extracellular traps. These apparent contradictions call for more thorough investigations into the role of eDNA and DNase in CF biofilm infection.
\end{abstract}

Keywords: Cystic Fibrosis, Pseudomonas aeruginosa, biofilm, extracellular DNA, DNase

J Dhaka Med Coll. 2013; 22(1) : 77-86.

\section{Introduction:}

Role of Pseudomonas aeruginosa in cystic fibrosis Cystic Fibrosis (CF) is a very common and lethal autosomal recessive genetic disease caused by mutations on chromosome 7 within the $\mathrm{CF}$ transmembrane conductance regulator (CFTR) gene. The most common mutation " $\Delta 508$ " is deletion of three nucleotides resulting in the loss of the amino acid phenylalanine at the 508 position of the protein. The CFTR protein resides at the epithelial surface of vital organs like lungs and functions to regulate ion and water content at the luminal surface. ${ }^{1}$ Therefore, any defect in this transmembrane chloride channel results in accumulation of mucus secretions in areas like the airway passage where it interferes with the natural airway clearance system. This mucus obstruction often aggravates to inflammation, bronchitis, pneumonia and even death in chronic patients.

$\mathrm{CF}$ is the most common infection among Caucasian population with estimated occurrence ratio of 1 in 2500 births. ${ }^{2}$ Infants with CF are usually born with hypertrophy of submucosal glands with inflammation occurring within the first few months of birth. $\mathrm{CF}$ lungs are initially colonised by organisms like Staphylococcus aureus or Haemophilus influenza but with time is soon predominated by Pseudomonas aeruginosa. . $^{2,3}$

1. Syed AK Shifat Ahmed, School of Life Sciences, Independent University, Bangladesh (IUB), Dhaka, Bangladesh.

2. James SG Dooley, Faculty of Life and Health Sciences, School of Biomedical Science, University of Ulster, Northern Ireland, United Kingdom.

3. Dr. Sudip Ranjan Deb, Resident Physician, Dhaka Medical College Hospital, Dhaka

4. Dr. Debesh Chandra Talukder, Assistant Professor, Dept. of ENT, Dhaka Medical College Hospital, Dhaka

5. Dr. Sheikh Shahinoor Hossain, Assistant Professor, Department of Respiratory Medicine, Dhaka Medial College, Dhaka

6. Dr. ASM Tanim Anwar, IMO, Department of Medicine, Dhaka Medical College Hospital, Dhaka

Correspondence: Syed A. K. Shifat Ahmed, School of Life Sciences, Independent University, Bangladesh (IUB), 16 Aftabuddin Ahmed Road, Block B, Bashundhara, Dhaka. Email: saksa86@yahoo.com. 
P. aeruginosa from $\mathrm{CF}$ patients has been widely studied because of its pathogenesis and strong resistance to host's defence and antibiotic treatments. The bacteria are trapped within the thick lung mucus and are surrounded by an exopolysaccharide (EPS) matrix called biofilm. Pseudomonas especially the mucoid forming ones possesses great risk to the body. It is because they often lose their flagellum thereby making the organism virtually invisible to the body's immune system (e.g. bacteria lacking flagellin do not trigger cytokine production) which allows them to survive the initial stages of infection without being recognised. ${ }^{2,4}$ The pathogenesis of mucoid forming strains can be interpreted from the data that $85 \%$ of the Pseudomonas strains isolated from the $\mathrm{CF}$ patients are in fact mucoid in nature. ${ }^{5}$ The mucoid nature arises from the alginate in the EPS of the biofilm matrix. ${ }^{6}$ This biofilm helps to protect the organism in the CF airways by inhibiting phagocytosis and retarding antibiotic exposure as described later in section 4 .

Pseudomonas aeruginosa biofilms in Cystic Fibrosis patients

A biofilm can be defined as a well-organized amalgam of bacteria which are nested in a selfproduced polymer matrix made of polysaccharide, protein and DNA. ${ }^{7,8}$ Bacterial biofilm causes chronic infection as they show tolerance to most antibiotics, disinfectant chemicals and body's innate and adaptive immune arsenals like phagocytosis. ${ }^{9,10}$

Biofilm development has been meticulously studied over the years in vitro by confocal scanning laser microscopy. The technique which uses green fluorescent protein (GFP) tagged bacteria has shown that Pseudomonas aeruginosa produces a mature biofilm in vitro within 5-7 days. ${ }^{11,12}$ The biofilm development takes place through several steps including bacteria attachment, microcolony formation, biofilm maturation and dispersion (Fig.-1).

Numerous studies have suggested that bacterial motility is an important factor in biofilm formation and development. ${ }^{13,14}$ Bacteria use their flagella mediated motility to establish contact with the surface by

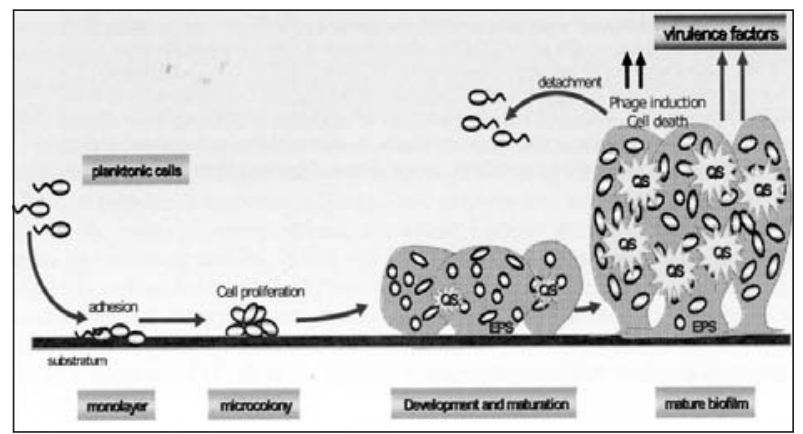

Fig.-1: Planktonic bacteria reversibly bind to the surface (at this stage the bacteria is most susceptible to antibiotics) irreversible binding to the surface followed by multiplication to form microcoloniesproduction of polymer matrix around the microcolonies the colonies grow and mature and the biofilm gets thicker (max tolerance to antibiotics) focal areas of biofilm dissolves and liberated bacteria cells spreads to another area. ${ }^{9}$

overcoming repulsive forces between the bacteria and its attached surface. ${ }^{15}$ Apart from flagella, bacteria use their type IV pili for twitching motility which contribute in formation of microcolonies during the biofilm development. However, these suggestions were rejected by Klausen et al. ${ }^{11}$, stating that these structures as not necessary for biofilm formation. To elucidate both the sides of the argument Deligianni et al. ${ }^{16}$ studied bacterial motility in clinical isolates from $\mathrm{CF}$ patients and showed that there exist a wide diversity in which different isolate could establish infection in CF lungs. The study showed $47 \%$ of the isolates were non-motile and of the motile isolates some showed twitching ability, some flagella mediated motility while some showed both.

The early Pseudomonas strains in CF lungs appear to be mostly non-mucoid and rapidly dividing in nature, however during chronic infection the bacteria acclimatize via genetic adaptation and mutations. ${ }^{16}$ For example mutation in mucA gene causes transition from non mucoid to alginate producing mucoid phenotype giving the bacteria increased virulence. Apart from alginate, in P.aeruginosa at least two more exopolysaccharides namely Psl and Pel have shown to contribute in biofilm development. ${ }^{17} \mathrm{Ma}$ et al. ${ }^{10}$ showed the importance of one of these, polysaccharide 
synthesis locus (Psl), in biofilm development. The Psl protein is anchored to the cell surface during attachment step and promotes cell to cell interactions allowing the bacteria to be glued firmly to the biofilm. When the biofilm matures the Psl assembles at the periphery of the microcolonies thereby leaving a "Psl matrix free cavity" where the dead cells and extracellular DNA accumulates before being released in the dispersion stage.

\section{QS in Pseudomonas biofilm}

Bacteria in biofilm can coordinate with each other through cell to cell communication via production of 'Quorum Sensing' (QS) signal molecules or autoinducers. The ability to generate cell signals allows the bacteria to sense and respond to environmental stress. ${ }^{18}$ $P$. aeruginosa has two QS systems; las which directs the synthesis of the homoserine lactone autoinducer $\mathrm{C}_{12}$-HSL and rhl which synthesizes the other autoinducer $\mathrm{C}_{4}-\mathrm{HSL}^{19}$. These QS systems have been linked with formation of biofilm and production of virulence factors like extracellular enzymes and cellular lysins in P.aeruginosa [e.g. rhamnolipid whose importance in P.aeruginosa infection was reported by Jensen et al. ${ }^{20}$ ] Jensen et al. ${ }^{20}$ experimentally showed that cell membrane of polymorphonuclear neutrophil (PMN), which are the first phagocytes to arrive during P.aeruginosa lung infection, are damaged by a compound present in the supernatants of (i) wild type PAO 1 and (ii) Ä lasrhl 1 mutant strains supplemented with $\mathrm{C}_{4}-\mathrm{HSL}$ and $\mathrm{C}_{12}{ }^{-}$ HSL.However the necrotic effect of the compound, later identified as 'rhamnolipid', was not observed in supernatants of ÄlasIrhlI and ÄlasRrhlR mutants. This observation supported the idea that QS molecules are involved in producing certain virulence factors and compounds like rhamnolipidthat facilitates biofilm development in lungs by averting host's immune defense.

Role of membrane vesicles in Pseudomonas aeruginosa infection

Membrane vesicles (MV) are bilayer spherical structures with an average diameter of 50 to $250 \mathrm{~nm}$ depending on the strain. ${ }^{21,22}$ They contain outer membrane protein (OMP), lipopolysaccharide (LPS), phospholipid and encapsulating periplasmic components (Fig 2) with some studies also stating the membrane vesicles to contain extracellular DNA. ${ }^{19,22}$ The vesicles in P.aeruginosa also contain certainvirulence factors like proelastase and phospholipase which when released into the surroundings can cause damage to host cells. ${ }^{23}$

The membrane vesicles can also be used as a carrier for transferring beneficial material between bacteria thereby contributing to genetic diversity and bacterial survivability in unfavorable conditions. ${ }^{24} \mathrm{P}$. aeruginosa vesicles are released during the early stationary growth phaseand are reported to transfer antibiotic resistance enzymes to other bacteria thereby also aiding in the survival of its neighboring bacteria against antibiotic influx. ${ }^{19}$

A recent study has shown $P$. aeruginosa $\mathrm{MV}$ to contain QS signaling molecule 2-heptyl-3hydroxyl-4-quinolone (Pseudomonas quinolone signal [PQS]), ${ }^{25}$ and antibacterial quinolone which functions in regulating the expression of multiple virulence factors (like rhamnolipid production) in the bacteria.

\section{Antibiotic resistance of bacterial biofilm}

Bacteria in biofilm have shown increased resistance not only to host's innate and adaptive immune system but also to many conventional antibiotics thereby making the biofilm forming bacteria a potent agent for chronic infections like cystic fibrosis. There are number of factors which might contribute to this resistance as described below.

\section{Low oxygen concentration and slow growth during stationary phase}

Within the interior part of biofilm, the presence of gradients can create areas of anoxic and acidic zones. This might result in nutrient depletion thereby causing the bacteria to behave like in 'stationary phase dormancy. ${ }^{26,27}$ Studies have revealed very slow in situ growth of P.aeruginosa from the sputum of $\mathrm{CF}$ patients suggesting that nutrient depletion may have an important role in conferring antibiotic resistance. ${ }^{9}$ Moreover, protein synthesis and metabolic activity have also shown to decrease 
as we move down from the periphery to the center of the biofilm. In addition it has been found that PMNs in the CF airways consumes oxygen and liberates reactive oxygen species that react with biofilm-embedded Pseudomonas aeruginosa. $^{28}$ This sets an imbalance between oxidative burden and antioxidant defenses thereby contributing to the oxidative stress in the biofilms.

\section{Efflux pump}

Up-regulation in the efflux pump has allowed $P$. aeruginosa biofilm to be resistant to a number of antibiotics. The organism has been shown to resist azithromycin (AZM) by causing expression of different genes in the efflux pump operon as well as disrupting the expression of two gene clusters. ${ }^{18}$ Similarly other efflux pumps have been identified which confers tolerance to antibiotics such as (a) MexCDOprJ and MexEF-OprN to ciprofloxacin and (b) MexXY-OprM to tobramycin. ${ }^{29,30}$

\section{Mutation}

Biofilm encased bacteria shows a higher mutation frequency than planktonic bacteria with increased frequency in horizontal gene transfer. Biofilm cultures of Pseudomonas showed an increase in mutability by $105-$ foldcompared to planktonic culture thereby giving the biofilm bacteria higher tolerance to antibiotics like rifampicin and ciprofloxacin ${ }^{31}$. $P$. aeruginosa shows strong resistance to âlactam antibiotics. In $2.5 \%$ of clinical $\mathrm{CF}$ isolates; complete 'de-repression' in â lactamase production was observed resulting in increased resistance to â lactam antibiotics, regardless of the presence of efflux pump. ${ }^{32}$

\section{Low permeability of the biofilm matrix}

The presence of thick biofilm gives the bacteria extra protection from different antibiotics. Although the biofilm matrix may not offer complete protection but it may delay the rate of antibiotic penetration long enough to induce the expression of other antibiotic resistance genes. ${ }^{33}$ The biofilm matrix has shown to retard the diffusion of certain antibiotics like â lactams and aminoglycosides but not to fluroquinolones. The ability of certain antibiotics to be more effective in destroying biofilm bacteria could be due to the bacteria's synergistic arrangement between the diffusion retardation of the biofilm wall and degradation ability of certain compounds as observed in case of degradation of â lactam antibiotics by â lactamase.

\section{Extracellular DNA inPseudomonas aeruginosa} It has been reported by Tetz ${ }^{34}$ that extracellular DNA (eDNA) of about $30 \mathrm{~kb}$ is an universal component in many gram negative and gram positive bacterial biofilms. The extracellular matrix of P.aeruginosa biofilms contains eDNA which acts as a cell to cell interconnecting compound for maintaining the 3D biofilm architecture. ${ }^{35}$ Several reviews have stated the presence of significant concentration of extracellular or free DNA in nature,like the aquatic environment has eDNA concentration of upto $44 \mu \mathrm{g} / 1 .^{36}$ Even in the lungs of $\mathrm{CF}$ patients, high amount of DNA (as high as 20 $\mathrm{mg} / \mathrm{ml}$ ) has been detected in the sputum. ${ }^{37,38}$ Researchers have suggested the origins of eDNA to be the membrane vesicles which are liberated from the matrix of P.aeruginosa into the surroundings during the organism's normal growth ${ }^{39}$. A recent study has suggested that QS is involved in releasing the extracellular DNA. This study found that the amount of LPS and DNA released was higher in wild type PAO 1 and las QS mutants-supplemented with $\mathrm{C}_{12}{ }^{-}$ HSL compared to las QS mutants alone; suggesting that QS regulation is involved in the release of DNA in P.aeruginosa. (19) Additional sources of DNA in the biofilm matrix might be from the dead bacteria and the immune cells like neutrophils. Although cell lysis has been thought to be a source of eDNA for many biofilm organisms like Staphylococcus aureus, ${ }^{40}$ the discovery of eDNA in young Pseudomonas biofilms, ${ }^{41}$ where cell lysis is not a frequent process suggest that this may not be the only source of DNA.

At physiological concentration extracellular DNA in $P$. aeruginosashows antimicrobial activity but at sub inhibitory concentration, DNA can chelate cations and create a cationlimited environment which stimulates the induction of antimicrobial peptide resistance operon PA3552-PA3559. These results in 2560- 
fold increased resistance to antimicrobial peptides and a 640 fold higher resistance to aminoglycosides. ${ }^{42} \mathrm{~A}$ more recent study showed the chelation of $\mathrm{Mg}^{2+}$ by DNA and EDTA results in a $\mathrm{Mg}^{2+}$ limited media which can induce biofilm formation by repressing the expression of the biofilm repressor gene, Ret S. ${ }^{43}$ This study contradicted the observation by an earlier study which showed EDTA as a potent biofilm disrupter. ${ }^{44}$ This difference in behavior of EDTA could be because the concentration of EDTA used in the earlier study was almost 10 times higher than that used for the later one.

The role of eDNA in early biofilm establishment was studied by Whitchurch. ${ }^{41}$ They firstly confirmed the presence of DNA in biofilm matrix by showing that during alginate synthesis in P.aeruginosa, the majority of the extracellular material when subjected to calorimetric assay gave a strong peak at absorbance $260 \mathrm{~nm}$ which when followed with electrophoretic and DNase sensitivity studies confirm the presence of high amount of DNA in the extracellular matrix. Secondly they investigated the effect of DNase on biofilm formation and found that PAO 1 cells colonized well and formed biofilm when grown in 'DNase lacking' medium as compared to when the medium was supplemented by DNase where they formed very few attached cells. Thirdly they tested the ability of DNase to dissolve established biofilmsand found that when P.aeruginosa biofilm of various ages $(12,36$ and 60 hours old) were transferred to DNase containing medium, the biofilm dissolved. But interestingly when an 84 hour old biofilm culture was inoculated in the DNase medium, a minor degree of biofilm dissolution was observed suggesting that there might be presence of other substances in an 'established biofilm' which could produce adequate proteolyticexoenzymes to counteract the activity of the DNase. This overall study was therefore successful in establishing the importance of eDNA in the early stages of P.aeruginosa biofilm formation.

Mulcahy ${ }^{45}$ showed that extracellular DNA can be used by $P$. aeruginosa (PAO 1) as a nutrient source. P. aeruginosa cells were grown in chemically defined medium where fish sperm DNA was used as a sole source of nitrogen, carbon or phosphate. Growth assays results showed highest peaks at $\mathrm{OD}_{600}$ for cells which used DNA as phosphate source followed by cells which used DNA as nitrogen and as carbon sources respectively. However no growth was observed in medium which lacked DNA as well as these three nutrients. Therefore, extracellular DNA not only contributes to biofilm formation and antibiotic resistance but also acts as a source of nutrient for $P$. aeruginosa at nutrient depleted sites.

\section{DNase in biofilm forming bacteria}

Extracellular DNA is a universal component of EPS matrix in biofilm forming bacteria. It has already been discussed that biofilm resist antibiotic and host's immune attack. But ongoing research has found that virulence of these biofilm forming pathogens can be reduced by use of DNase especially when used in combination therapy with antibiotics.

DNase reduces biofilm tolerance to antibiotics Tetz and $\mathrm{Tetz}^{46}$ reported that when growth of Pseudomonas in culture was supplemented with DNase, it formed biofilms with a lower biofilm biomass as well as with a reduced bacterial biomass. The study used light microscopy and spectrometric measurements for the following observations. The biofilm biomass of Staphylococcus aureusand Escherichia coli decreased by $51 \%$ and $54 \%$ as the DNase concentration was gradually increased from $0.1 \mu \mathrm{g} / \mathrm{ml}$ to $100 \mu \mathrm{g} / \mathrm{ml}$. Microscopic observation revealed that bacterial cells treated with DNase gave increased cell-free areas compared to the untreated one ${ }^{47}$.

When antibiotics (50 times its MIC) were used along with DNase $(5 \mu \mathrm{g} / \mathrm{ml})$, the treatment had a significant reducing effect on the biofilm biomass and total bacterial biomass. However when antibiotics were used in monotherapy the reduction observed was comparatively much less in most cases (Table-I). These results suggest that (i) extracellular DNA is important in developing biofilm tolerance and (ii) biofilm formation is affected by DNasethereby 
resulting in lower tolerance to antibiotics and immune attacks.

\section{$P$. aeruginosa uses DNase to extract nutrients from extracellular DNA}

Extracellular DNase activity has already been observed in $P$. aeruginosa strain and isolates from $\mathrm{CF}$ patients (e.g. PAK, PA14, PA103) with the XCP type II secretion system playing a major role in it. Mulcahy ${ }^{45}$ reported that under phosphate limited condition $P$. aeruginosa is capable of using extracellular DNA as a nutrient source by inducing the expression of PA3909 gene, which codes for a DNase, in presence of $\mathrm{Mg}^{2+}$ and $\mathrm{Ca}^{2+}$. This study showed that in media lacking carbon, nitrogen and phosphorous (as a whole or separately), addition of 5 or $10 \mu \mathrm{g} / \mathrm{ml}$ of DNase resulted in increased growth of wild type PAO1 cells in the log phase in a dose-dependent manner (Fig. 3A). Comparable result of growth was also observed for culture which used succinate, ammonium nitrate and phosphate buffer instead of DNA as C, N and P sources. However, PA3909 mutant

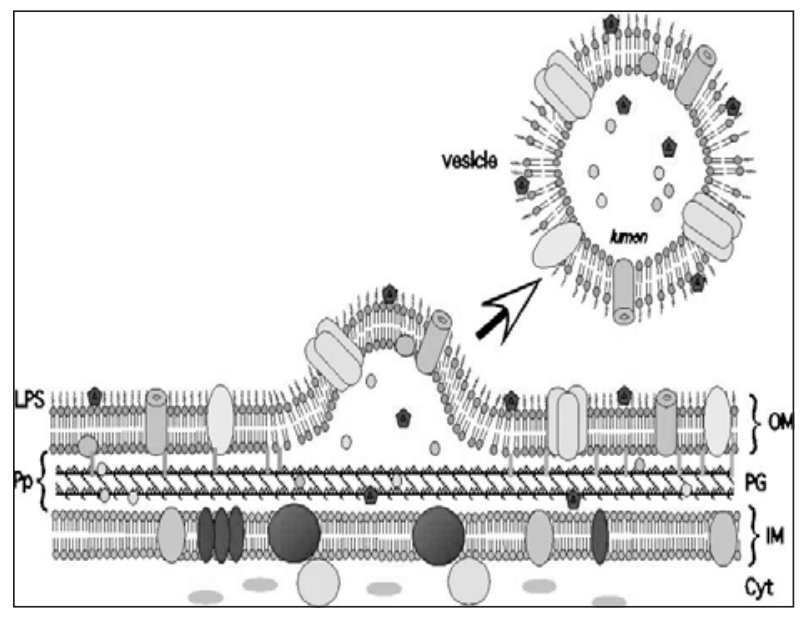

Figure 2: Model of vesicle biogenesis- Outer Membrane (OM) vesicles are proteoliposomes consisting of OM phospholipids and LPS, a subset of OM proteins, and periplasmic (luminal) proteins. Proteins such as LT (red) that adhere to the external surface of the bacteria are associated with the external surface of vesicles. Proteins and lipids of the Inner Membrane (IM) and cytosolic content are excluded from OM vesicles. Vesicles are likely to bud at sites where the links between the peptidoglycan and OM are infrequent, absent, or broken. ${ }^{24}$

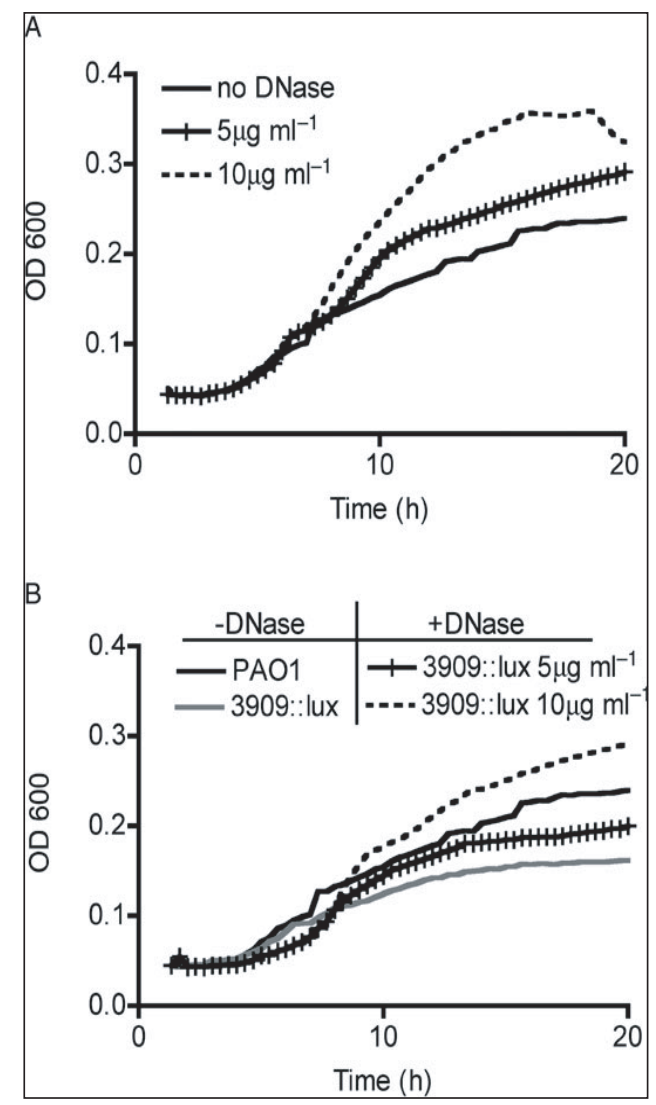

Figure 3: A) PAO1 growth in carbon, phosphate and nitrogen limited media in presence and in absence of DNase, B) PAO1 mutant growth in media containing DNA as phosphate source in presence and in absence of DNase.

(PA 3909::1ux) showed decreased growth compare to wild type when DNA was used as the phosphate source but on addition of exogenous DNase growth rate of the mutant cells were reverted to higher level (Fig. 3B). These observations suggest that P.aeruginosa uses PA 3909 gene to secrete DNase for degrading extracellular DNA. The bacteria then use the degraded DNA for growth by using itmainly as a source of phosphate.

\section{DNase degrade neutrophil extracellular traps}

Previous studies have commented that extracellular DNase have a role in disseminating infecting bacteria by lysing pus, ${ }^{46}$ while more recent studies hypothesize that DNase can help bacteria evade one of host's immune attacks by degrading the neutrophil extracellular trap (NETs). ${ }^{48,49}$ NETs are antimicrobial proteins that capture and kill 
Pseudomonas Aeruginosa Infection in Cystic Fibrosis Patients

Ahmed SAKS et al

Table-I

Antibiotics when used in combination with DNase has a more significant reduction effect on E.coli and S.aurues biofilms

\begin{tabular}{lcccc}
\hline Treatment & \multicolumn{3}{c}{ Reduction in biofilm biomassReduction in total bacterial biomass } \\
& E. Coli & S. aureus & E. coli & S. aureus \\
\hline Ampicillin & $11-15 \%$ & $11-15 \%$ & $16-24 \%$ & $16-24 \%$ \\
Ampicillin and DNase & $18 \%$ & $19 \%$ & $66-67 \%$ & $66-67 \%$ \\
Levofloxacin & $32 \%$ & $11 \%$ & $58 \%$ & $40 \%$ \\
Levofloxacin and DNase & $44 \%$ & $57 \%$ & $78 \%$ & no change \\
\hline
\end{tabular}

pathogens. But the DNA component of NET can be degraded if the activated neutrophils are exposed to DNase secreted by the organism. ${ }^{49}$ DNase can also passively affect neutrophil recruitment as studies have shown that neutrophil activation decreases when Pseudomonas biofilm is treated with DNase 1 which causes the degradation of the biofilm DNA. In another study it has been shown that DNase 1 like 2 (DNase1L2) to be the first human DNase capable of preventing biofilm infection in a standard assay system. ${ }^{50}$ However, this leads to a question, DNase 1 being a human endonuclease should also be present in $\mathrm{CF}$ patients and therefore should be able to degrade the DNA in the biofilm, destabilizing the biofilm structure and making biofilm infection more easily curable, but does it happen? Probably not! This could possibly be due to the binding of the DNase 1 to actin monomers which have been shown to be present in $\mathrm{CF}$ sputum, ${ }^{51}$ thereby making the enzyme inactive and preventing the degradation of biofilm DNA.

\section{Current treatment strategy:}

At present some methods have been adopted for treating and preventing chronic P.aeruginosa infections in $\mathrm{CF}$ patients. These include (a) isolation techniques combined with hygiene practices for preventing crossinfection from already infected patients, ${ }^{52}$ (b) antibiotic treatment like ciprofloxacin, nebulisedcolistin or nebulised tobramycin in the early stages of the infection to suppress biofilm formation, ${ }^{53}$ and (c) nebulized DNase (Pulmozyme ${ }^{\circledR}$ ) on a daily basis to reduce the viscosity of DNA containing lung sputum ${ }^{54}$. These treatments when used in monotherapy or in combination have been able to reduce the risk of infection and prolong the life span of the patients especially in cases of young children.

\section{Conclusion:}

Although $P$. aeruginosa infection in $\mathrm{CF}$ patients have been controlled to a certain level but risk still remains as different strains mutates at high frequency showing increased resistance to antibiotics. The use of external DNase in clearing the mucus viscosity is promising butfurthertestsshould be done to see if the DNase produced bythebacteriainvivo can be regulated to prevent it from degrading the neutrophil extracellular traps.

According to the above mentioned studies an interesting mystery about the role of DNase is that, on one hand it contributes to the virulence of Pseudomonasby degrading the NETs and breaking down DNA for nutrient accessibility, while on the other hand it reduces the pathogenesis by degrading the bacterial biofilm thereby making the pathogen more susceptible to antibiotics treatment. So how can DNaseboth enhance as well as negate $\mathrm{CF}$ infection need further research. It would be interesting to see whether all or only some selected strains of Pseudomonas aeruginosa produces this DNaseand whether the constituents within the biofilmenvironments in lungslike - presence of cations $\mathrm{Mg}^{2+}$, $\left.\mathrm{Ca}^{2+}\right)$ have any influence on DNase production. If these puzzles can be solved then CF infection can be better treated and prevented.

\section{References:}

1. Nichols DP, Konstan MW, Chmiel JF. Antiinflammatory therapies for cystic fibrosis related lung disease. Clin Rev Allergy Immunol 2008; 35: 135-53. 
2. Hassett DJ, Korfhagen TR, Irvin RT, Schurr MJ, Sauer K, Lau GW, et al. Pseudomonas aeruginosa biofilm infections in cystic fibrosis: insights into pathogenic processes and treatment strategies. Expert Opin Ther Targets 2010; 14(2): 117-30.

3. Mulcahy H, Charron-Mazenod L, Lewenza S. Pseudomonas aeruginosa produces an extracellular deoxyribonuclease that is required for utilization of DNA as a nutrient source. Environ Microbiol 2010; 12(6): 1621-9.

4. Garrett ES, Perlegas D, Wozniak DJ. Negative control of flagellum synthesis in Pseudomonas aeruginosa is modulated by the alternative sigma factor AlgT (AlgU). J. Bacteriol 1999; 181(23): 7401-4.

5. Fick Rb Jr, Sonoda F, Hornick DB. Emergence and persistence of Pseudomonas aeruginosa in the cystic fibrosis airway. Semin Respir Infect 1992; 7: $168-78$.

6. Govan JR, Deretic V. Microbial pathogenesis in cystic fibrosis: Mucoid Pseudomonas aeruginosa and Burkholderia cepacia. Microbiol Rev 1996; 60: 539-74.

7. Bjarnsholt T, Jensen PØ, Fiandaca MJ, Pedersen $\mathrm{J}$, Hansen CR, Andersen CB et al. Pseudomonas aeruginosa biofilms in the respiratory tract of cystic fibrosis patients. Pediatr Pulmonol 2009; 44: 54758.

8. Costerton W, Veeh R, Shirtliff M, Pasmore M, Post C, Ehrlich G. The application of biofilm science to the study and control of chronic bacterial infections. J Clin Investig 2003; 112:1466-77.

9. Høiby N, Bjarnsholt T, Givskov M, Molin S, Ciofu O. Antibiotic resistance of bacterial biofilms. Int $\mathrm{J}$ Antimicrob Agents 2010; 35: 322-32.

10. Ma L, Conover M, Lu H, Parsek MR, Bayles K. Assembly and Development of the Pseudomonas aeruginosa Biofilm Matrix. PLoS Pathogens 2009; 5(3) [accessed on 02 August, 2012]. Available from: http: / / www.plospathogens.org/article / info\%3Adoi\%2F10.1371\%2Fjournal.ppat. 1000354

11. Klausen M, Heydorn A, Ragas P, Lambertsen L, Aaes-Jorgensen A, Molin S et al. Biofilm formation by Pseudomonas aeruginosa wild type, flagella and type IV mutants. Mol Microbiol 2003; 48:151124.

12. Heydorn A, Ersboll B, Kato J, Hentzer M, Parsek MR, Tolker-Nielsen T, et al. Statistical analysis of Pseudomonas aeruginosa biofilm development: impact of mutations in genes involved in twitching motility, cell-to-cell signaling, and stationary-phase sigma factor expression. Appl Environ Microbiol 2002; 68: 2008-17.
13. Mattick JS. Type IV pili and twitching motility. Annu Rev Microbiol 2002; 56: 289-314.

14. Pratt LA, Kolter R. Genetic analysis of Escherichia coli biofilm formation: roles of flagella motility chemotaxis and type I pili. Mol Microbiol 1998; 30: 285-93.

15. Sauer K, Cullen MC, Rickard AH, Zeef LA, Davies DG, Gilbert P. Characterization of nutrientinduced dispersion in Pseudomonas aeruginosa PAO 1 biofilm. J Bacteriol 2004; 186: 7312-26.

16. Deligianni E, Pattison S, Berar D, Ternan NG, Haylock RW, Moore JE et al. Pseudomonas aeruginosa cystic fibrosis isolates of similar RAPD genotype exhibit diversity in biofilm forming ability in vitro. BMC Microbiol 2010; 10 (38): NA.

17. Ryder C, Byrd M, Wozniak DJ. Role of polysaccharides in Pseudomonas aeruginosa biofilm development. Curr Opin Microbiol 2007; 10: 6448.

18. Hall-Stoodley L, Stoodley P. Evolving concepts in biofilm infections. Cell Microbiol 2009; 11(7): 1034-43.

19. Nakamura S, Higashiyama $\mathrm{Y}$, Izumikawa K, Seki M, Kakeya H, Yamamoto $Y$ et al. The roles of the quorum sensing system in the release of extracellular DNA, lipopolysaccharide and membrane vesicles from Pseudomonas aeruginosa. Jpn J Infect Dis 2008; 61: 375-8.

20. Jensen PO, Bjarnsholt T, Phipps R, Rasmussen TB, Calum H, Christoffersen L et al. Rapid necrotic killing of polymorphonuclear leukocytes is caused by quorum-sensing-controlled production of rhamnolipid by Pseudomonas aeruginosa. Microbiology 2007; 153: 1329-38.

21. Tashiro Y, Sakai R, Toyofuku M, Sawada I, Nakajima-Kambe $\mathrm{T}$, Uchiyama $\mathrm{H}$ et al. Outer Membrane Machinery and Alginate Synthesis Regulator Control Membrane Vesicle Production in Pseudomonas aeruginosa. J Bacteriol 2009; 191(24): 7509-19.

22. Beveridge T J. Structures of gram-negative cell walls and their derived membrane vesicles. J Bacteriol 1999; 181: 4725-33.

23. Li Z, Clarke A, Beveridge TJ. Gram-negative bacteria produce membrane vesicles which are capable of killing other bacteria. J Bacteriol 1998; 180: 5478-83.

24. Kuehn MJ, Kesty NC. Bacterial outer membrane vesicles and the host-pathogen interaction. Gene Dev 2005; 19: 2645-55.

25. Mashburn L, Whiteley M. Membrane vesicles traffic signals and facilitates group activities in a prokaryote. Nature 2005; 437:422-5. 
26. Fux CA, Wilson S, Stoodley, P. Detachment characteristics and oxacillin resistance of Staphyloccocus aureus biofilm emboli in an in vitro catheter infection model. J Bacteriol 2004; 186: 4486-91.

27. Walters MC, Roe F, Bugnicourt A, Franklin MJ and Stewart PS. Contributions of antibiotic penetration, oxygen limitation, and low metabolic activity to tolerance of Pseudomonas aeruginosa biofilms to Ciprofloxacin and Tobramycin. Antimicrob Agents Chemother 2003; 47: 317-23.

28. Kolpen M, Hansen CR, Bjarnsholt T, Moser C, Christensen LD, Van-Gennip $M$ et al. Polymorphonuclear leucocytes consume oxygen in sputum from chronic Pseudomonas aeruginosa pneumonia in cystic fibrosis. Thorax 2010; 65: 57-62.

29. Islam $\mathrm{S}, \mathrm{Oh} \mathrm{H}$, Jalal $\mathrm{S}$, Ciofu O, Høiby $\mathrm{N}$, Wretlind B. Chromosomal mechanisms of aminoglycoside resistance in Pseudomonas aeruginosa isolates from cystic fibrosis patients. Clin Microbiol Infect 2009; 15: 60-6.

30. Jalal S, Ciofu O, Høiby N, Gotoh N and Wretlind B. Molecular mechanisms of fluoroquinolone resistance in Pseudomonas aeruginosa isolates from cystic fibrosis patients. Antimicrob Agents Chemother 2000; 44: 710-12.

31. Driffield K, Miller K, Bostock M, O’Neill AJ, Chopra I. Increased mutability of Pseudomonas aeruginosa in biofilms. J Antimicrob Chemother 2008; 61: 1053-6.

32. Ciofu O. Pseudomonas aeruginosa chromosomal âlactamase in patients with cystic fibrosis and chronic lung infection: Mechanism of antibiotic resistance and target of the humoral immune response. APMIS 2003; 116: 1-47.

33. Jefferson KK, Goldmann DA, Pier GB. Use of confocal microscopy to analyze the rate of vancomycin penetration through Staphylococcus aureus biofilms. Antimicrob Agents Chemother 2005; 49: 2467-73.

34. Tetz GV, Artemenki NK, Tetz VV. Effect of DNase and antibiotics on biofilm characteristics. Antimicrob Agents Chemother 2009; 53: 1204-9.

35. Bass JIF, Russo DM, Gabelloni ML, Geffner JR, Giordano M, Catalano M et al. Extracellular DNA: A Major Proinflammatory component of Pseudomonas aeruginosa biofilms. J Immunol 2010; 184 (11): 6386-95.

36. Lorenz MG, Wackernagel W. Bacterial gene transfer by natural genetic transformation in the environment. Microbiol Rev 1994; 58: 563-602.

37. Ulmer JS, Herzka A, Toy KJ, Baker DL, Dodge $\mathrm{AH}$, Sinicropi D, et al. Engineering actin-resistant human DNase I for treatment of cystic fibrosis. Proc Natl Acad Sci 1996; 93: 8225-29.

38. Brandt $\mathrm{T}$, Breitenstein $\mathrm{S}$, von der Hardt $\mathrm{H}$, Tummler B. DNA concentration and length in sputum of patients with cystic fibrosis during inhalation with recombinant human DNase. Thorax 1995; 50: 880-2.

39. Kadurugamuwa JL, Beveridge TJ. Virulence factors are released from Pseudomonas aeruginosa in association with membrane vesicles during normal growth and exposure to gentamicin: a novel mechanism of enzyme secretion. J Bacteriol 2008; 177: 3998-4008.

40. Rice KC, Mann EE, Endres JL, Weiss EC, Cassat JE, Smeltzer MS et al. (2007). The cidA murein hydrolase regulator contributes to DNA release and biofilm development in Staphylococcus aureus. Proc Natl Acad Sci 2007; 104: 8113-8.

41. Whitchurch CB, Tolker-Nielsen T, Ragas PC, Mattick JS. Extracellular DNA required for bacterial biofilm formation. Science 2002; 295(22): 1487.

42. Mulcahy H, Charron-Mazenod L, Lewanza S. Extracellular DNA chelates cations and induces antibiotic resistance in Pseudomonas aeruginosa biofilms. PLoS Pathogens. 2008; 4(11) [accessed on 02 August, 2012]. Available from: http:// www.plospathogens.org/ article/info\%3Adoi\% 2F10.1371\%2Fjournal.ppat. 1000213

43. Mulcahy H, Lewenza S. Magnesium limitation is an environmental trigger of the Pseudomonas aeruginosa biofilm lifestyle. PLoS ONE. 2011; 6(8) [accessed on 02 August, 2012]. Available from: http: / / www.plosone.org/article/info \% 3 Adoi\%2F10.1371\%2Fjournal. pone.0023307

44. Banin E, Brady KM, Greenberg EP. Chelatorinduced dispersal and killing of Pseudomonas aeruginosa cells in a biofilm. Appl Environ Microbiol 2006; 72(3): 2064-9.

45. Mulcahy H, Charron-Mazenod L, Lewenza S. Pseudomonas aeruginosa produces an extracellular deoxyribonuclease that is required for utilization of DNA as a nutrient source. Environ Microbiol 2010; 12(6): 1621-9.

46. Tetz VV, Tetz GV. Effect of extracellular DNA destruction by DNase I on characteristics of forming biofilms. DNA Cell Biol 2010; 29(8): 399405.

47. Sherry S, Tillet WS, Christensen LR. Presence and significance of deoxyribose nucleoprotein in the purulent pleural exudates of patients. Exp Biol Med 1948; 68: 179-84.

48. Brinkmann V, Reichard U, Goosmann C, Fauler B, Uhlemann Y, Weiss DS et al. Neutrophil 
extracellular traps kill bacteria. Science 2004; 303 : 1532-5.

49. Buchanan JT, Simpson AJ, Aziz RK, Liu GY, Kristian SA, Kotb $\mathrm{M}$ et al. DNase expression allows the pathogen group A Streptococcus to escape killing in neutrophil extracellular traps. Curr Biol 2006; 16: 396-400.

50. Eckhart L, Fischer H, Barken KB, Tolker-Nielsen T, Tschachler E. DNase1L2 suppresses biofilm formation by Pseudomonas aeruginosa and Staphylococcus aureus. Br J Dermatol 2007; 156: 1342-5.

51. Walker TS, Tomlin KL, Worthen GS, Poch KR, Lieber JG, Saavedra MT et al. Enhanced Pseudomonas aeruginosa biofilm development mediated by human neutrophils. Infect Immun 2005; 73(6): 3693-3701.

52. Høiby N, Pedersen SS. Estimated risk of crossinfection with Pseudomonas aeruginosa in Danish cystic fibrosis patients. Acta Paediatr Scand 1989; 78: 395-404.

53. Döring G, Høiby N. Early intervention and prevention of lung disease in cystic fibrosis: a European consensus. J Cystic Fibrosis 2004; 3: 67-91.

54. Frederiksen B, Pressler T, Hansen A, Koch C, Høiby N. Effect of aerosolized rhDNase (Pulmozyme ${ }^{\circledR}$ ) on pulmonary colonization in patients with cystic fibrosis. Acta Paediatr Scand 2006; 95:1070-4. 